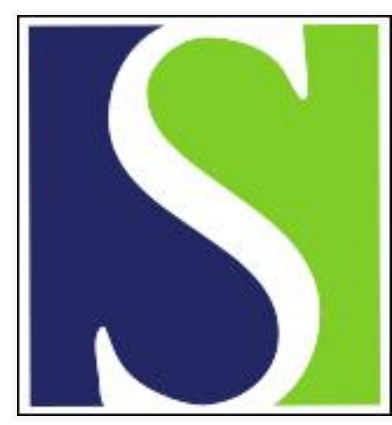

Scand J Work Environ Health 1999;25(6):473-483

https://doi.org/10.5271/sjweh.469

Issue date: Dec 1999

\title{
Research challenges arising from changes in worklife
}

by Rantanen J

The following article refers to this text: $2008 ; 34(6): 463-470$

Key terms: future worklife; information society; occupational health; prevention; promotion; research challenge

This article in PubMed: www.ncbi.nlm.nih.gov/pubmed/10884142

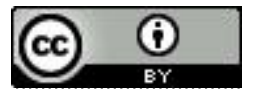




\title{
Research challenges arising from changes in worklife
}

\author{
Jorma Rantanen, $M D^{1}$
}

\begin{abstract}
Rantanen J. Research challenges arising from changes in worklife. Scand J Work Environ Health 1999;25(6, special issue): $473-483$.

Great challenges for occupational health research are set by the rapid changes in the world of work as a consequence of globalization, new technologies, demographic workforce changes, fragmentation of enterprises and work contracts, high time pressures, high demands for learning new skills, and growing worker mobility. The occupational health problems are of 2 types, the persistent and reemerging old problems of occupational injuries and diseases and new challenges from psychological stress, musculoskeletal disorders caused by computerized work, cognitive ergonomics in information-intensive work, the work ability of aging workers, and new trends in occupational allergies. The 3 roles of research, improvement of knowledge, improvement of understanding, and support of the development of work conditions in practice, all call for new initiatives in occupational health research. The new comprehensive strategy for the development and promotion of work ability has been found to respond effectively to these new needs.
\end{abstract}

Key terms occupational health, research challenges, future worklife, information society, prevention, promotion.

The role of research in society is (i) to increase our knowledge of nature, people and society, (ii) to increase our understanding of these 3 components of life, and (iii) to provide a scientific basis for actions to make a better world through the prevention and control of adverse trends (eg, global warming, technology hazards, poverty, emerging new and old diseases) and through amplifying and facilitating positive developments (eg, new methods for agricultural and food production, clean technologies, ensuring decent work for all, and promotion of economic and social development in the least developed countries). Occupational health research is active in all
3 roles, and its position in the development of worklife will be even more important in the future than it has been in the past. While some of the earlier visionaries saw the role of occupational health as time-limited, making itself unnecessary in the future through effective prevention of hazards and risks, this article provides arguments for the endless need for occupational health research with high relevance for the development of worklife and for a sustainable social, economic and ecological future in general.

Due to several simultaneously acting factors, the change in worklife is accelerating (figure 1), and it will

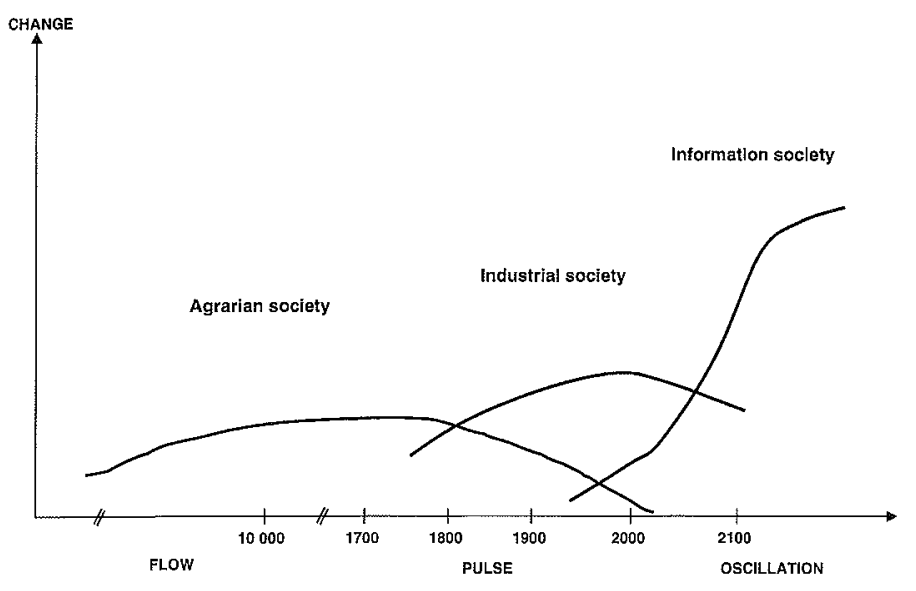

1 Finnish Institute of Occupational Health, Helsinki, Finland.
Figure 1. Increasing pace of change in the 3 types of societies. (See table 1.)

Reprint requests to: Professor J Rantanen, Finnish Institute Occupational Health, Topeliuksenkatu 41 a A, FIN-00250 Helsinki, Finland. [jorma.rantanen@occuphealth] 
become continuous after being more stepwise in the past. Such a change has several parallel developments (eg, growth of global trade, changes in enterprise structures, penetration of new technologies to all sectors, changes in political objectives, growing role of media, environmental concerns, quantitative and qualitative changes in working populations, demographic developments of general populations, and major social and behavioral changes). All these factors affect the development of work and work conditions, safety, and health at work. They also very much determine the directions and conditions of operation for research. Most of all, they present new problems and challenges to researchers and those who use and apply research results. Some of the trends and changes of greatest importance are discussed in this article. Although worklife is in the forefront of the change, the new trends affect all parts of society and its functions (table 1).

\section{New trends at the macro and micro level}

\section{Globalization}

Globalization can be defined as an increase in the total world economic activity as a consequence of the liberalization of trade and the elimination of the hindrances to the transfer of capital, goods, and services across borders. Widescale use of communication and information technologies facilitates such interaction $(1-3)$. In practice, globalization is seen as growing economic transactions, as an increase in direct foreign investments, and as an increase in world trade (growth in the $1990 \mathrm{~s}+7 \% /$ year) faster than the world total production (with an average growth of $2-3 \% / y e a r)$. The global operations require larger companies than before. A growing number of the 50000 multinational companies in the world are merging to form larger giant enterprises that can individually exceed the size of the economy of a mediumsized country. Simultaneously, their role in world economy has grown. For example, General Motors has a larger economic volume than the national economy of
Denmark, while Ford, Toyota, and Exxon each constitute a larger economy than Norway, Poland, or Portugal. The top 5 multinational corporations exceed the total economic volume of the 30 least-developed countries by more than 10-fold, and they have a larger economy than South Asia and Sub-Saharan Africa together. This situation implies that the policies in worklife and the resources allocated for developing worklife by multinational companies are of utmost importance. There may also be differences between the policy of a global multinational corporation and the national policies on occupational health and safety. Fortunately, many of the leading companies have adopted a responsible policy and even transfer good examples and practices to the areas where they operate, but also less positive examples exist. There is a universal need to study the effects of globalization on health and safety at work and to provide scientific bases for universal minimum standards for work conditions.

\section{Fragmentation}

Parallel to the growth in the size of the multinational companies, national enterprises adapt to the new demands set by growing competition by increasing their flexibility (4). The most important strategies for this step are fragmenting the company into smaller independent decentralized units that often work as networks, outsourcing activities to smaller units, subcontracting, and developing flexible work organizations. Additional methods used to attain flexibility are, for example, the recruitment of a portion of personnel on a fixed-term or temporary basis, the organization of flexible workhours, and the establishment of new employment relationships with "e-lance" or "tele-workers".

The consequences of such fragmentation are partly positive and partly negative for health and safety, and fragmentation also affects the conditions of research in several different ways. About 100 million of the 140 million workers in the European Union work in about 15 million small or medium-size enterprises and in an equal number of workshops of self-employed people $(5,6)$. Their work conditions vary greatly, as do their possibilities to carry out occupational safety and health

Table 1. Three types of societies

\begin{tabular}{|c|c|c|c|}
\hline Feature & Agrarian society & Industrial society & Information society \\
\hline Culture & Local & National & Global \\
\hline Economy & Natural & Industrial & Global network economy \\
\hline Resources & Natural & Hydro, fossile, nuclear energy & $\begin{array}{l}\text { Hydro, fossile, nuclear, bioenergy, wind, ocean, } \\
\text { geothermal energy }\end{array}$ \\
\hline Type of work & Dynamic, muscular & $\begin{array}{l}\text { Dynamic muscular work, static and } \\
\text { repetitive manual work }\end{array}$ & Mental and brain work \\
\hline Work organizations & Family, village & Company and public institution & Company, public institution or NGO and their networks \\
\hline Organization of work & Self-steered, families & $\begin{array}{l}\text { Line-organization directed towards } \\
\text { objectives, operation and results }\end{array}$ & $\begin{array}{l}\text { Networks of organizations, team-operated } \\
\text { autonomously, management by results }\end{array}$ \\
\hline Source of knowledge & Tradition, experience & Natural and engineering sciences & Natural, bio-, behavioral and social sciences \\
\hline
\end{tabular}


activities. Without special support they cannot participate in research projects and initiate preventive and control intervention. While the traditional physicochemical, ergonomic, and accident hazards are higher than in large companies, the general work climate and the relationships between managers and workers and the degree of selfsteering seem to be more favorable in small and medium-sized enterprises (7). The fragmentation of worklife is likely to grow in the future, and therefore the problems of small enterprises deserve more attention. Important research questions are how to get sufficient information on conditions of work, health, and safety in small and medium-sized enterprises, how to make such small enterprises and self-employed persons effective users of occupational health research, and how to provide them with the services needed for improving their work conditions.

\section{Demographic trends}

The demography of the world's 6 billion population as a whole is aging due to 2 macro-scale trends. First, the population growth has declined to an average level of $1.5 \%$ a year, and, $2 \mathrm{nd}$, the improved health situation has substantially increased life expectancy in almost all countries of the world (8). Particularly, the industrialized countries and, first of all, Western Europe and Japan face the challenge of their 600 million work force aging in the next $2-3$ decades $(9,10)$. There is growing concern about the development of old-age dependency ratios and the sustainability of social security schemes (11).

The question of postponing retirement ages and preventing the exclusion of workers from work because of age are topical issues on the political agenda. A likely development, which is already visible in some countries, is the elevation of the stipulated retirement age by 2 to 3 years to correspond to increased life expectancies. A prerequisite for the success of such new policies is good health and work ability, sufficient competence and skill, and the ability to change to acceptable new jobs.

Simultaneously with the aging work force, a shortage of young labor is foreseen, and therefore higher productivity pressures are expected for those in the middle of their worklife. In view of such future trends, which are likely to continue up to 2030 , one of the key research challenges is to ensure the work ability of aging persons and to ensure their participation in active worklife up to the stipulated retirement age. This effort requires the adaptation of work to the worker and the promotion of his or her health, work ability, competence, and skill to correspond with the new job demands. In many countries the workforce reserves will be recruited to worklife in the next decade, and the most important source will be the women of working age. We also need research on the effect of aging on both physical and mental work capacity. Particularly, the question of the aging individual as the user of modern information technology and the development of age-related criteria for information technology and information-intensive work needs to be answered in the next decade $(12,13)$.

\section{New technology}

The introduction of information and communication technologies (ICT) has grown with accelerating rates in all parts of the world, and it does not show any signs of leveling off (1). New technologies penetrate worklife in all sectors of the economy, starting from schools, the public sector, industries, and the service sector. In the industrialized countries, such as Finland, 50-100\% of employees use computers at work. The number of mobile phones and Internet hosts has grown by 40 -fold in the 1990s. The use of the new information and communication technologies will make several "old skills" outdated, and simultaneously new competence profiles will be generated. New ICT occupations are the most rapidly growing groups of employees in general, and even in the countries with relatively high unemployment rates, such as Finland, there is a severe shortage of ICT experts. New technologies also change the job contents, organization of work, and competence demands for workers.

There is a major research question about how best to adjust the new technology and the new complex work environment to the competence, work ability, and aspirations of people at work and how to ensure the longterm sustainability and productivity of the new humantechnology relationships. Research is needed in 3 main areas, the demands on the visual and auditory sensory system in the design of information and communication technologies, cognitive ergonomics in computerized information-intensive work and the manual ergonomics of ICT worksites and the organization of information work. Although severe health hazards from nonionizing radiation of ICT use are unlikely to occur, the principle of prudence implies the need for strengthening research and risk assessment in this area.

The foreseeable ICT developments during the next 5 years speak for increasing mobility of well-equipped communication tools and for mobile worksites. This situation predicts the possibility to work increasingly at any time and place without the limitations of a fixed worksite. How such "nomadic" work will be organized on the long term and how to ensure health and safety remains to be researched.

The new information and communication technologies have made many old jobs outdated, and the new jobs that have been generated have totally new competence demands. At least in the transition phase, the risk of unemployment is expected to increase as a consequence of the use of the new information and communication technologies (14), and the most pessimistic estimates speak for chronic unemployment in the future at high 
percentage levels (15). The adverse effects of unemployment on health and work ability have been found to increase as the duration of the unemployment increases. Research is needed to design strategies for preventing a negative health impact and for promoting employability and the maintenance of work ability during unemployment (13). Fortunately, recent findings show, however, the positive impact of information and communication technologies on productivity and, locally, on employment $(16-18)$.

\section{Challenges in occupational health research}

\section{Dynamic base lines}

The rapid and continuous change in enterprise structures, work contracts, and employment patterns and the growing national and international mobility of working people make the previously stable base lines, such as lifelong contracts and stable work environments, very unlikely for a substantial part of the working population. The regular monitoring of the work environment and health becomes discontinuous and, in many cases, impossible. Due to major changes in company structures, company-based data may become less important in the future than individual-based data. How the monitoring of workers will be organized is still an unanswered question. Epidemiology, for example, has so far been developed intensively to manage the problems of outcome definition, control of confounders and modificators, the combination of cohort and case-control studies, and the handling of multiple exposures and their combinations in comparatively stable environments. Much benefit has been obtained for public health from epidemiologic studies of workers who have been heavily exposed and who, as homogeneous groups, have made the follow-up for long periods possible. The homogeneity of the working population, the stability of workplaces, and the long duration of work contracts have permitted study designs that have not been possible in general populations. Relatively stable industry-based communities and their inhabitants have also offered a good basis for community-level research. Now this stability is becoming rarer and rarer, and we have to generate new methods to follow, register, and assess workers' health, both exposures and outcomes of workers who have high turnover rates and increased heterogeneity and mobility and who are scattered into large geographic areas permitting often only short periods of follow-up.

The growing international mobility makes such follow-up even more demanding. It also affects further the homogeneity of many working populations. For example, ethnic diversity is a new aspect in the personnel of many previously national-level companies, and this diversity needs to be considered in the assessment of responses and outcomes in health as a consequence of occupational exposures. International migration also changes the traditional nonoccupational morbidity panoramas of workers who may contract diseases in the new endemic environments or transfer endemic diseases of one region to another $(19,20)$.

The new information technologies (eg, personal smart cards) permit the registration of data practically without quantitative limits. Research should be directed towards developing systematic approaches for organizing the monitoring of health and safety data in new global and national environments irrespective of the type of employment. Research efforts are also needed for making reliable summaries of personal occupational histories and occupational exposures collected from several short-term pieces in several enterprises or in varying jobs. New methods of risk assessment are needed to improve the analysis of the exposure burden on the worker from several different environments. The available technologies will make this work possible, but several aspects of the organization of data confidentiality and also data security and protection problems may appear as obstacles. The transition from static "storage registers" to more dynamic and interactive "functional registers" may become actual in the near future.

If such information follows the workers themselves on "personal" cards that are completed in the course of the work career, its utilization for research purposes will become possible and can counteract the obstacles caused by fragmentation. Such a smart card could be utilized also for several other purposes, including health services, and for social security, and, for example, the recognition of the onset of the first symptoms of an occupational disease. It is, however, vital to ensure appropriate protection of the confidentiality of data in the use of such cards.

\section{Exposures}

Exposure trends have changed in several ways in modern society and in the new forms of worklife, including changes in levels, which tend to decline, and in duration, pattern, composition, and combination. Still some 30$50 \%$ of working populations are exposed to traditional occupational safety and health hazards, such as chemicals, physical factors like noise, heavy and unergonomic work, biological factors, and the like $(21,22)$. Instead of being individual chemical, physical or biological agents or their combinations, combinations of several different types of factors must be increasingly dealt with, for example, various forms of work organization, physical or mental work loads of various degree added to changing - often very complex - worktime schedules, totally 
new work environments (eg, telework, new management and payment systems), and new structures of work teams and social relations at the workplace, double jobs, and new social settings in civil life. For example, the great variation in workhours has made the standard exposure time calculations on the 8-hour basis very irrelevant for about 1/3 of the work force in Finland (23).

Several new exposure concepts need to be considered. For example, most service workers today have other human beings as the object of their work, and their most prevalent exposure is the human-human interaction between the service worker and the client. Such exposures have numerous psychological and psychosocial dimensions (eg, emotional load in caring occupations or threat of violence in several services) and parameters different from the traditional physicochemical and biological exposures, which may also be involved (24).

Fragmentation and mobility make the identification of the sources, the follow-up, and the assessment of exposures more difficult than before. For example, the collection of data on exposures during the whole work career of an aged worker may suffer from more inaccuracies than earlier because of high numbers of job rotation. The short life-span of about $1 / 3$ of the newly-established enterprises in Finland, for example, makes the establishment of long-term trends at the workplace impossible.

Internationalization makes workers and other people move geographically into culturally and socially new environments with numerous, and often unknown exposures, confounders, and modifiers - new nutritional habits, new leisure-time and social activities, and new constructed and biological environments. The distinction between occupational and nonoccupational effects may become more difficult (and irrelevant), and the management of confounders may become more complex. Similarly, the actions for prevention at other than the individual level may become difficult or impossible, for example, because of the law, practice, or culture of the new host country. As in the case of the monitoring of baseline data, also the monitoring and collection of data on actual exposures need new approaches. Due to numerous movements from one environment to another there may be a growing need for personal monitoring in addition to environmental monitoring, which may become difficult. Such internationalization also calls for the generation of universal minimum standards to provide a scientific basis for risk assessment (25).

\section{Health outcomes}

There are some 50 major occupational diseases listed in official lists and textbooks of occupational medicine (25). Many of the industrialized countries see declining morbidity in such traditional diseases as chemical poisonings, pneumoconioses, vibration-induced vasospastic syndrome, or noise-induced hearing loss, while "workrelated" diseases increase in occurrence (26). Some of the "old" diseases, such as asbestos-related cancers, however, will continue to increase still for 2-3 decades (27).

In addition to traditional health outcomes, also a number of new outcomes will be met with a totally new character and often with a multifactorial and multicausal origin. Instead of a search for definite diseases, the interest in modern worklife is focused increasingly on functional capacity and behavioral, environmental and social determinants of work ability, work motivation, and the quality of worklife in general. In addition to specific health problems, new aspects, such as productivity, quality of products, innovation, capacity to handle clients, and life-long work ability, are being given growing attention. These outcomes are often ill-defined and cannot necessarily be measured with existing methods. The interindividual variation in outcomes may be wide and confounded by several new factors either at work or outside of work. The outcomes, such as the reduction of functional capacity or work ability can also be very context-dependent. A typical example is the work ability index (WAI), which is dependent on both the capacity of the worker and the demands of the job (13). Another example is the risk of burnout, which is highly dependent on the person's resources, but also on the context of work and on several factors occurring at the workplace $(23,28)$. Such a new development calls for a qualitative research approach to complement the quantitative one.

\section{Musculoskeletal disorders}

In most of the western industrialized countries, musculoskeletal disorders constitute a major cause of work disability and premature retirement. The exposures associated with musculoskeletal morbidity vary widely, and for only a minor portion of diseases is the etiology known. The musculoskeletal disorders associated with the aging of the working population, with previous traumas and overloads, heavy work load, and unergonomic work conditions need to be further studied to find the risk exposures, mechanisms of action, and targets for prevention $(29,30)$.

There is also a need to develop validated methods for the measurement of exposures and to sharpen the criteria for outcomes in order to identify more in detail the possible associations between work conditions and health. The development of research on physical work load and the risk of injury of the musculoskeletal system, particularly in light physical work, such as that done at worksites with visual display units, is also necessary. Simultaneously the combined effects of psychological stress and unergonomic work with hand-arm systems on musculoskeletal morbidity need to be studied $(31,32)$. The challenge for basic research is the elucidation of the 
biomedical mechanisms of various musculoskeletal disorders, starting from mechanisms of arthrosis, injury of muscular and connective tissue structures by static and repetitive work load and ending up with studies on the etiology of chronic muscular and connective tissue pain.

\section{Hypersensitivity}

Allergies and other hypersensitivity diseases are gaining more importance in the whole population, and allergies are one of the most rapidly growing groups of occupational diseases. The increasing hypersensitivity of the young population increases the number of susceptible people entering worklife. There are several research needs in relation to occupational allergies, for example, the identification and risk assessment of allergens at work, the determination of indicators for immunologic properties of allergenic exposures, and the development of early and more specific indicators for immunologic hypersensitivity responses. Some new exposures, such as mold contamination in wet buildings and its impact on health, still require study, and the characterization of exposures, the outcomes, and studies of the causal associations and risk assessment are needed (33-35).

\section{Stress-related disorders}

An increasing prevalence of mental work, the introduction of new technologies with demands for the quick learning of their use, high time pressure, long workhours, unconventional workshifts, information overload, poor work climate at the workplace, high pressure for increased productivity, continuous change, adaptation to new work organizations, uncertainty about continuation of employment, threat of violence at work, and high emotional load in certain care-giving occupations all increase the psychological load of working people and may lead to stress reactions. One of the key issues from the health point of view is the organization of flexible workhours. Several different models have been utilized in Europe, the United Kingdom, and the United States (36), and these models differ substantially in their consequences to health (37). While the total annual worktime has decreased in the past 120 years by $30-50 \%$ in the industrialized countries, productivity has grown by 1000 $4000 \%$, and the gross domestic products of various countries by 500 to $2600 \%$ (38). Although most of the productivity has been obtained through technology, also better organization, intensive use, and increased competence of human resources have played a role. Stress is the consequence of the overuse of human capacities at work.

According to recent studies, over 50\% of Finnish workers, $54 \%$ of workers in the European Union, and equal numbers of workers in the United States perceive high time pressures, growing demands at work, and long workhours as factors increasing stress at work $(23,22$, 39). Particularly the combination of high demands at work and a low degree of control of work conditions by the employees themselves seems to increase stress reactions. Time pressure at work is one of the factors signaling both a high demand and a low degree of freedom. Continuous unreasonable stress has been found to be associated with an elevated risk of somatic diseases, such as coronary heart disease and hypertension $(40,31,39)$, and evidence of an increased risk of musculoskeletal disorders under stress is increasing (32). A look at the development of the conditions of work in modern worklife and predictions of trends for the next 5 to 10 years support the expectation that occupational stress in its different forms, and derived from different sources, will be one of the major occupational health epidemics of the next decade.

The research challenges are many, including the identification of the factors at work and outside work that contribute to stress, an explanation of wide interindividual variation in stress reactions, the development of "objective" indicators for stress reactions and particularly for the risk of ill health and the development of preventive measures at the individual, workplace, and company level. There is a special need to develop early indicators of psychological overload and the risk of exhaustion in order to enable preventive actions in time. Occupational stress is not only an issue of individual stress management capacity, but also a question of work organization. The optimal way to organize work in view of stress prevention needs to be studied further. A multidisciplinary approach in such research is likely to be the most fruitful.

\section{How should the three roles of research be carried out in the future?}

There are 2 types of research questions asked, first, new questions concerning old problems, such as how to prevent the risk of accidents in modern work environments (so-called zero accident strategy) and, for example, the question concerning the immunologic mechanisms of work-related allergies. Another group of questions concerns the assessment and management of new hazards and risks, such as the potential health effects of new communication technologies and, for example, the impact of new work organizations on health. The new demands of information-intensive work on the cognitive performance of the worker are one of the key questions determining the health and productivity of the information society.

\section{Increasing knowledge}

In rapidly changing worklife the routine registers of exposures, problems, and outcomes are at risk of lagging behind real developments. To get an up-to-date situation 
analysis on health, safety, and other aspects of worklife in rapidly changing environments requires new strategies for the compilation of information. Quick field surveys with modern information and communication technologies will substantially facilitate such information collection. Internet-based questionnaires and computer-assisted telephone interviews (CATI) provide the infrastructures for such activities. Computer-assisted systems should also be maximally used for making an analysis of collected data and for transmitting the information to users. The possibilities provided by new information and communication technologies and new software have so far been less effectively utilized (41).

Modern biomedical, psychological, and behavioral sciences produce markers and indicators for exposures and conditions that can affect health, and growing numbers of indications for the early effects of such conditions are also being developed. It is the challenge for occupational health research to scrutinize carefully such new opportunities and assess their feasibility for occupational health practice. In such developments the issues of ethics, the protection of human dignity and integrity, and the confidentiality of data need to be considered (42).

New structural developments in the collection of information and its registration need also to be made because of fragmentation. While company files contain data on big enterprises only, the growing numbers of selfemployed and small and medium-sized enterprises remain uncovered. Even for these types of workplaces the surveillance strategy may be the most effective solution. With the help of information and communication technologies, such a collection of information can be organized so that the data produced in routine services and other activities are automatically transmitted to the research units or to registers. Internet-based real-time monitoring systems are under development and may become an important tool for data compilation.

Modern technologies permit registration and monitoring of almost endless numbers of parameters for humans at work (often by telemetric techniques) and of the work environment, tools, machines and processes. Such high numbers of data are difficult to transmit, analyze and process into comprehensible results. It may be possible to process them more effectively by using modern computing methods, for example, learning neural networks, which can be used in the organization and analysis of high volumes of complex information. Such an experiment is currently underway in analyzing multifactoral indoor air problems.

\section{Understanding}

Due to the growing complexity of the world of work there are several activities aiming at understanding the relationship between health and work. Modern analysis and visualization methods provide new possibilities for generating user-friendly syntheses of results. Developments in mathematics and biostatistics provide new possibilities for modeling that help generate a comprehendible picture of complex phenomena (43-45).

Another level of understanding concerns studies relating exposures and other conditions of work to health effects (ie, elucidation of the etiology of problems). This process may require detailed and deep-going studies of mechanisms to understand how health effects are generated. Mechanism studies are also important for generating hypotheses for population studies, for confirming the conclusions on observed associations in epidemiologic studies, and for identifying the precise targets for prevention. The establishment of dose-response relationships is of utmost importance in the future, particularly in view of risk assessment. Risk assessment is one of the key tools in the management of adverse health effects. There is a need to develop additional risk assessment methods that are sensitive not only for risks derived from the past, but which also are able to predict the risks of the future.

The $3 \mathrm{rd}$ level of research improving understanding is the analysis and evaluation of the consequences of the exposure, the conditions, or the activity of concern. Such an analysis is needed for both the evaluation of consequences to health and for the analysis of social and economic consequences. New methods for consequence analysis have been developed for economic appraisal, and particularly in environmental impact assessment they are very practice oriented $(46,47)$. In complex worklife the causality between the exposing factor and the health outcomes may occur at different levels. There are direct and visible factors observed at the local or enterprise level, while the question of why such factors occur at work may be determined at a totally different level and by totally different factors. The elucidation of such "causes of causes" is an important step in the understanding of the picture as a whole and in the targeting of actions for prevention and promotion.

\section{Making an impact on practices}

If extrapolated from the Finnish data, occupational health research produces a world output of a maximum of 35000 reports annually (about $0.3 \%$ of the total world annual research output of 1.151 million reports). It is generally assumed that a substantial part of such research remains unused and lacks any application. No systematic analysis of the degree of utilization of occupational health research has so far been made.

While the justification of financing applied research is its proved utility value, it is important to study how research results are put into practice. Such "research on research" is relatively scarce, and even the paradigm for such studies is not well developed. One of the few systematic approaches is the national program for tobacco control of the Department of Health and Human 
Services in the United States. The biomedical basic research approach is followed by applied research and ultimately by research on applications and intervention. Each stage has its own research paradigm and research questions to be answered. In the rapidly changing society, all these steps may need to be studied in parallel as they previously were researched consecutively. For this purpose, large research programs, instead of individual projects, are needed (48).

Since the implementation of results in real life practice may differ from the effects obtained in experimental settings, it is important to test the feasibility in practice, starting with implementation stepwise on a limited scale and, if appropriate, ending with full-scale system-wide intervention.

The application of research is closely dependent on the knowledge and understanding that develops through training and practical experience (figure 2). The routes of application of occupational health research results may be multiple, training, information, guidelines, standards or norms, service methods or practices, inspection practices, intervention, and the like. The use of route or their combinations may vary according to situation. Typical for occupational health programs, several routes are used simultaneously. For example, the Finnish Asbestos Program employed legislation and standard setting, training and counseling, intervention, information campaigns, surveys and screening, and practical guidelines to eliminate the further use of new asbestos and to make the demolition work safer. The scope of application was wide, covering 6 different jurisdictions under public administration, and all the main industries which used or were exposed to asbestos were involved (49).

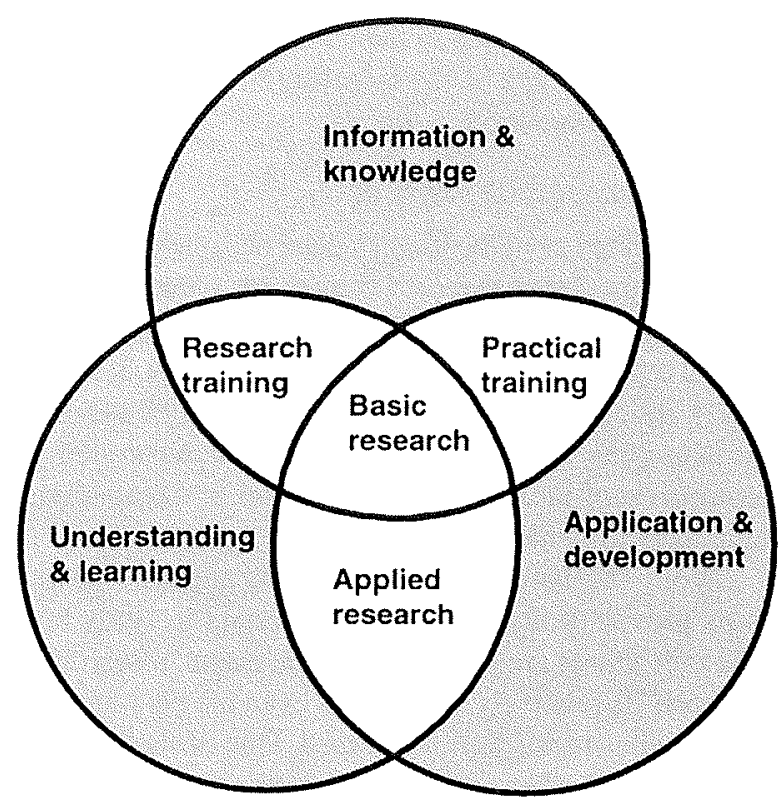

Figure 2. Three roles of research and their relation to training.
A new approach to making an impact in practice for the development of workers' work conditions, health, and safety and also to supporting the overall development of the enterprise has been generated in Finland. The approach to the maintenance and promotion of work ability comprises a comprehensive multidisciplinary program for the improvement of health, work ability, safety, work organization, and management, plus the development of professional competence of both employees and managers. This approach requires the workers' own activity, but it is supported by external occupational health services or by organizational development experts. On the basis of massive research over the past 20 years, the Finnish Institute of Occupational Health has collected packages of validated methods for good practice in the maintenance and promotion of work ability, particularly for expert use (50). The experiences are so far positive; more than $80 \%$ of Finnish employees work at workplaces where a work ability program has been implemented and over $85 \%$ of both workers and managers are convinced of the positive impact on health, work ability and the economy of the company. Activity to maintain and promote the work ability of employees is well on its way to becoming an important instrument for strengthening both the overall development and sustainability of companies and the health and well-being of employees $(50,51)$.

The application of research in the future may become more demanding for several reasons. First, the multicausal, multifactoral character of problems makes actions more complex. The fragmentation of worklife scatters the targets and makes them difficult to cover. Unemployed persons are easily dropped out. The dynamic change in base lines does not permit long-term follow-ups, and participation of target populations and enterprises is becoming more difficult to arrange. While big enterprises are able effectively to participate in such programs with the help of their own resources, the growing numbers of smaller enterprises and the self-employed need external support, both expert and financial (7).

Some new strategies have been experimented with in view of making an impact on the scattered system. Branch-oriented intervention in collaboration with respective branch organizations or commercial chambers has been successfully utilized in several programs. Community-based activities covering a certain geographic area were effective in the prevention of accidents at work and in the community. Internet networks between research institutions and target enterprises or occupational health units have been experimented with in Finland, and the WISE approach of the International Labour Organization operates in collaboration with commercial chambers that have good contacts with small and mediumsized enterprises $(7,52)$.

Research applications are needed in the prevention and control of both the traditional occupational health and 
safety hazards and their consequences and of problems related to new hazards. The new development-oriented approach not only focuses on prevention and control, but also on continuous improvement and the promotion of the health, safety and well-being of people at work, the good functioning of enterprises, the effective management of change, and continuous individual and collective learning at work. Such an approach provides a new paradigm for occupational health and safety, and it has been found to be productive in several aspects, in the improvement of health, safety, work ability and social relations and in terms of economy and productivity (53). The new approach also implies an ever-continuing need for research in occupational health in order to provide a sound scientific knowledge basis for continuous development. The most modern enterprises and institutions are gradually moving from the stage of risk-specific prevention to comprehensive promotion and development-oriented strategy, in which the ability to manage the change and provide responses to new demands of worklife are possible (figure 3).

Such development can be accelerated by competition. Competitions for the improvement of health and safety have been organized in a certain geographic area with excellent results, for example, improved order, tidiness, and safety measures at the workplace reduced accidents rates by $75 \%$ in a 2 -year period (54). The quality management systems imply continuous improvement of health and safety at enterprises. Such activity needs the development of instruments and new knowledge from research. There is a possibility to transmit such information to users through modern ICT networks (54).

\section{Summary}

The macro- and micro-scale trends described in this article will substantially change the conditions under which research in occupational health is carried out in the future. Great challenges are set by globalization, fragmentation, the introduction of new technologies, new work organizations, aging, and the increasing mobility of working populations. The dynamic changes in structures of worklife make the collection of data on exposures, hazards, the health of working people, and the impact of control measures more difficult than in the past. New innovative strategies using modern communication and information technologies need to be generated.

While many of the traditional health and safety problems, such as accidents and "old" occupational diseases still remain actual, several new health outcomes need to be considered, such as growing psychological stress and psychological overload, problems of information-intensive work and the intensive use of new information technologies, the maintenance and promotion of workers' work ability and, particularly, aging individuals, and the possible unexpected health hazards from new technologies, new allergies and new infections. Health impacts of new flexible work organizations and worktime schedules also need to be studied.

The 3 roles of research of improving knowledge, increasing understanding, and providing a sound scientific basis for developing practices will still be valid in the future, and they often need to be played in parallel rather than consecutively, as was done in the past. New strategies for taking health research as a tool for the overall



Figure 3. Evolution of occupational health strategies and the impact on social and economic dimensions. 
development of health, the environment, work ability, and work organization, plus the competence of workers and enterprises, provides a never-ending mission for occupational health research.

\section{References}

1. World Bank. World development report: knowledge for development, 1998/99. New York (NY): Oxford University Press, 1999.

2. Rantanen J. Impact of globalization on health. Paper presented at the XV IEA 99 international scientific meeting "Epidemiology for Sustainable Health", Florence, Italy, 31 August - 4 September 1999.

3. United Nations Development Program (UNDP). Human development report 1998. New York (NY): Oxford University Press, 1998.

4. Knauth P. Work organizations and work schedules in the future. In: Rantanen J, Lehtinen S, Huuhtanen P, Härmä M, Laitinen H, Lehtelä J, et al, editors. Work in the information society. Helsinki: Finnish Institute of Occupational Health, 1996:84-9. People and work, research reports, no 8.

5. Eurostat. Europe in figures. 4th ed. Luxembourg: Eurostat, the Statistical Office of the European Communities, 1996.

6. Rantanen J. Experiences and perspectives for prevention and development of occupational safety and health in small-scale enterprises. In: Lehtinen S, Vartio A, Rantanen J, editors. From protection to promotion: occupational health and safety in small-scale enterprises: proceedings of the international symposium, 4-6 May 1998, Helsinki, Finland. Helsinki: Finnish Institute of Occupational Health, 1998:82-90. People and work, research reports, no 25.

7. Bergström M, Huuskonen MS, Koskinen K, Lindström K, Kaleva S, Ahonen G, et al, editors. Työkyky, yksilön, pienyrityksen ja yhteiskunnan menestystekijänä [Work ability as a success factor of individual, society and small-scale enterprise]. Helsinki: Finnish Institute of Occupational Health, 1997. People and work, research reports, no 10.

8. World Health Organization (WHO). The world health report 1999: making a difference. Geneva: WHO, 1999.

9. Ilmarinen J. Ageing workers in the European Union - status and promotion of work ability, employability and employment. Helsinki: Finnish Institute of Occupational Health, Ministry of Social Affairs and Health, Ministry of Labor, 1999:274 p.

10. World Health Organization (WHO). World atlas of ageing. Kobe (Japan): Centre for Health Development, 1998.

11. Organization for Economic Cooperation and Development (OECD). Workforce ageing in OECD countries: employment outlook. : OECD, 1998:123-51.

12. Rantanen J, Lehtinen S. Tietoyhteiskunta, terveys ja työ [Information society, health and work]. Helsinki: SITRA, 1998. SITRA 164.

13. Ilmarinen J, Tuomi K, Klockars M. Changes in the work ability of active employees over an 11-year period. Scand J Work Environ Health 1997;23 suppl 1:49-57.

14. Freeman C, Soete L. Work for all or mass unemployment: computerised technical change into the 21 st century. London: Pinter Publishers, 1994:193 p.

15. Rifkin J. Technology, jobs and your future: the end of work: the decline of the global labor force and the dawn of the postmarket era. New York (NY): GP Putnam's Sons, 1996.

16. Pohjola M. Information technology and economic development: an introduction to the research issues. : The United Nations University WIDER, 1998. Working papers, no 153.

17. Brynjolfsson E, Hitt LM. Beyond the productivity paradox. Commun ACM 1998;41(8):49—55.

18. Statistics Finland. Tiedolla tietoyhteiskuntaan [With knowledge to information society]. Helsinki: Statistics Finland, 1997.

19. Kyrönseppä H. Kansainvälistyminen ja kansanterveys [Internationalization and public health]. In: Työterveyden Edistämisyhdistys. Kansainvälistyminen - haaste työelämälle [Internationalization - a challenge for work life]. Helsinki Työterveyden Edistämisyhdistys, 1999:34-5.

20. Hallauer J, Kane M, McCloy E, editors. Eliminating hepatitis $\mathrm{B}$ as an occupational hazard. London: Viral Hepatitis Prevention Board, 1993.

21. Kauppinen T, Aaltonen M, Lehtinen S, Lindström K, Näyhä S, Riihimäki H, et al, editors. Työ ja terveys Suomessa v 1997 [Work and health in Finland in 1997]. Helsinki: Finnish Institute of Occupational Health, 1997. English summary.

22. Paoli P. Second European survey of working conditions. Dublin: European Foundation for the Improvement of Living and Working Conditions, 1996

23. Kalimo R, Toppinen S. Työuupumus Suomen työikäisellä väestöllä [Exhaustion among work-age population in Finland]. Helsinki: Finnish Institute of Occupational Health, 1997.

24. Saarela K-L. Future challenges in preventing accidents at work, hoe, and in leisure. Presentation made at the Symposium on Safety in the Modern Society, 15-17 September 1999 Helsinki, Finland.

25. World Health Organization (WHO). Global strategy on occupational health for all. Geneva: WHO, 1995.

26. World Health Organization (WHO). Epidemiology of workrelated diseases and accidents. Geneva: WHO, 1989:71 p. Technical report series, no 777 .

27. Peto J, Hodgson J, Matthews F, Jones JR. Continuing in crease in mesothelioma mortality in Britain. Lancet 1995;345:535-9.

28. Maslach C. Job burnout: a review. In: Rantanen J, Lehtinen S, Kalimo R, Nordman H, Vainio H, Viikari-Juntura E. New epidemics in occupational health. Helsinki: Finnish Institute of Occupational Health, 1994:72-5. People and Work, research reports, no 1.

29. Viikari-Juntura E, Silverstein B. Role of physical load factors in carpal tunnel syndrome [review]. Scand J Work Environ Health 1999;25(3):163-85.

30. National Institute for Occupational Safety and Health (NIOSH). Musculoskeletal disorders and workplace factors. Cincinnati (OH): NIOSH, 1997.

31. Theorell T. Psychosocial factors at work in relation to musculoskeletal conditions - implications for job design and rehabilitation. Helsinki: Finnish Institute of Occupational Health. People and work, research reports. In press.

32. Westgaard RH. Effects of physical and mental stressors on muscle pain. In: PREMUS-ISEOH '98: 3rd international scientific conference on prevention of work-related musculoskeletal disorders, 13th international symposium on epidemiology in occupational health, 21-25 September 1998. Helsinki: Finnish Institute of Occupational Health, 1998. Abstracts 1,1998 .

33. Andersson K. Management of the sick building - investiga- 
tion strategies. In: New epidemics in occupational health. Helsinki: Finnish Institute of Occupational Health, 1994:117—20. People and work, research reports, no 1.

34. Nordman H. Building-related ill-health: strategies for the investigation of a sick building. In: New epidemics in occupational health. Helsinki: Finnish Institute of Occupational Health, 1994:234-7. People and work, research reports, no 1.

35. Vanhanen M, Tuomi T, Nordman H, Tupasela O, Holmberg PC, Miettinen M, et al. Sensitization to industrial enzymes in enzyme research and production. Scand J Work Environ Health 1997;23(5):385-91.

36. Bosch G. Working-time reductions and employment - lessons from Europe. Paper presented in a symposium of the Finnish Presidency of the European Union concerning working time in Europe: towards a European working time policy, 11-12 October 1999, Helsinki, Finland.

37. Härmä M, Tenkanen L, Sjöblom T, Alikoski T, Heinsalmi P. Combined effects of shift work and life-style on the prevalence of insomnia, sleep deprivation and daytime sleepiness. Scand J Work Environ Health 1998;24(4):300-7.

38. Maddison A. L'économie mondiale 1820-1992. Paris: Analyze et Statistiques, OECD, 1995.

39. Sauter S, Rosenstock L. Consequences of new patterns of work organisation. In: The changing world of work: conference proceedings, Bilbao 19-21 October 1998:60-2.

40. Karasek R, Theorell T. Healthy work: stress, productivity, and the reconstruction of working life. New York (NY): Basic Books, Inc, 1990:381 p.

41. Kähkönen E. Utilization of new information technologies in communication for small enterprises. Afr Newsl Occup Health Safety 1999;9 suppl 1.

42. Lehtinen S, Sorsa M, Rantanen J, editors. Ethical and social principles in occupational health practices: proceedings of the international symposium, 1-3 December 1997, Finland. Helsinki: Finnish Institute of Occupational Health, 1998:121 p. People and work, research reports, no 21.

43. Nurminen $\mathrm{M}$, Nurminen T, Corvalán CF. Methodologic issues in epidemiologic risk assessment. Epidemiology 1999;10(5):585-93.
44. Stayner L, Smith R, Bailer J, Luebeck EG, Moolgavkar SH. Modeling epidemiologic studies of occupational cohorts for the quantitative assessment of carcinogenic hazard. Am J Ind Med 1995;27:155-70.

45. McMichael AJ. Conceptual and methodological challenges in predicting the health impacts of climate change. Med War 1995;11(4):195-201.

46. Hammar JS. Economic analysis for health projects. World Bank Res Obs 1997;12(1):47-71.

47. Hansen SM. Arbejdsmiljö og samfundsökonomi - en metode til konsekvensberegning [Work environment and national economy - a method for consequence calculation]. Copenhagen: Nordisk Ministerråd 1993. Nord 22.

48. US Department of Health and Human Services. Cancer control phases applied to smoking and tobacco control research. Cincinnati $(\mathrm{OH})$ : US Department of Health and Human Services, 1991. Memorandum.

49. Finnish Institute of Occupational Health. Asbestos program 1987-92: final report. Helsinki: Finnish Institute of Occupational Health, 1992.

50. Rantanen J. The future challenges for occupational health. Presented at the European conference 'Healthy Employees in Healthy Organisations - Workplace Health Promotion in Europe', Bonn, Germany, May 31-June 1, 1999.

51. Peltomäki P, Pohjanpää K, Tuomi K, Liira J, Nykyri E, Piirainen $\mathrm{H}$, et al. Tyky-barometri: työkykyä ylläpitävä toiminta suomalaisilla työpaikoilla vuonna 1998 [Maintenance of work ability in the Finnish workplaces in 1998]. Helsinki: Finnish Institute of Occupational Health, Ministry of Social Affairs and Health, 1999:153 p.

52. Kogi K, Phoon W-O, Thurman E. Low-cost ways of improving working conditions: 100 examples from Asia. Geneva: International Labor Office, 1988:177 p.

53. Anttonen H, Piikivi L, Vuolteenaho A, Kopperoinen I. Työkyvyn taloudelliset vaikutukset [The economic consequences of work ability]. Helsinki: Finnish Institute of Occupational Health, 1998:89 p.

54. Laitinen H, Rasa P-L, Räsänen T, Nykyri E. An observation method as a tool for workplace risk assessment. Technol Law Insur 1998;3:57-61. 